

\title{
Has Futures Trading Affected the Volatility of Aluminium Transactions Prices?
}

\author{
Isabel Figuerola-Ferretti \\ Christopher L. Gilbert
}

Initial draft: 4 April, 2000

This revision: 7 December, 2000

\begin{abstract}
We consider how aluminium transactions prices have been affected by the development of futures trading in aluminium. Using a series for transactions prices constructed from a trade journal, we establish that both this series and the exchange cash price may be regarded as errorridden measures of the same latent variables. Furthermore, the error associated with the exchange price has declined over time. Tests provide weak evidence for a modest increase in volatility in the post-producer pricing period, but a VAR model suggests that this may be accounted for by the rapidly decaying "frothiness" of the exchange price, now increasingly reflected in transactions prices.
\end{abstract}

JEL classification codes: L61,G1,

Key words: aluminium, transaction prices, futures trading, price volatility

This is the revised version of a paper presented at a meeting of the Applied Econometrics Association, Luxembourg, 6-7 July 2000.

Figuerola-Ferretti: Department of Economics, Queen Mary, University of London, Mile End Road, London E1 4NS, UK, email i.figuerola-ferretti@qmw.ac.uk . Gilbert: FEWEC, Vrije Universiteit, De Boelelaan 1105, 1081 HV Amsterdam, The Netherlands, email cgilbert@econ.vu.nl. 


\section{Introduction}

Industrial raw materials are either priced by producers on a list price basis or are bought and sold at prices which are closely related to the prices of exchange-traded metals. List-based prices are often held to be less volatile than exchange prices, while exchange prices are more transparent. This transparency may restrict the ability of producers to discriminate amongst consumers. Firms which purchase these raw materials may be held to benefit from the effects of reduced transparency but suffer from the any associated increase in volatility. The benefits to them of exchange trading will therefore depend on the relative size of these two effects. We look at one side of this equation.

The final two decades of the twentieth century witnessed a major expansion in futures trading in the energy and non-ferrous metals markets. In this paper we focus on the aluminium market which, prior to the nineteen eighties, was dominated for most of the twentieth century by a small number of transnational smelting companies who set prices on an administered (list) basis. However, in the mid nineteen eighties, the aluminium industry moved to pricing on the basis of exchange prices. Aluminium therefore provides a natural experiment allowing us to examine the effects of exchange trading on price variability.

Trading in aluminium futures commenced on the London Metal Exchange (the LME) in October 1978, but the new market was relatively unimportant in its first few years of operation. However, from the mid eighties, the LME price became the industry marker price and commercial contracts for the supply of aluminium moved away from producer prices to pricing at an agreed premium or discount on LME prices at (or around) the date of delivery. US producers abandoned the practice of selling on a list price basis in 1986.

Standard texts emphasise that futures trading brings the social benefits of risk management through hedging, and of price discovery (see, eg, Edwards and Ma, 1992, p.13). In practice, these texts and the academic journal literature on futures markets discuss hedging and the associated risk issues at much greater length than price discovery. This reflects the theoretical and practical difficulties of analysing 
price discovery - see Stein (1986) for the most coherent attempt to do this. ${ }^{1}$ In this paper, we aim to make an empirical contribution to this literature.

Consumers are interested in the prices at which they transact, and also, if they are firms consuming intermediate products or raw materials, the prices at which their competitors transact. Although administered prices appear uniform, the administered pricing regime in aluminium (as in other non-ferrous metals) was associated with secret and variable discounts (Radetzki, 1990, p.81). Actual transactions prices were therefore neither stable nor transparent.

For these reasons, industries in which prices are set on a list basis are always welcome the availability of a common reference price. Possible reference prices are prices published in trade journals, and prices resulting from trading on centralised exchanges. Both offer transparency. However, trade journal prices, which are based on small and informal surveys, are often regarded as unrepresentative, while exchange prices are only representative of actual transactions prices if the underlying market is sufficiently liquid. In the European aluminium market, the London Metal Bulletin "certain other transactions" price was widely used as a reference price prior to the LME aluminium market becoming liquid. ${ }^{2}$ However, once the LME aluminium contract became liquid and producers retreated from pricing on a list basis, the aluminium industry moved to price contracts specified in terms of the "unknown" LME cash settlement price. ${ }^{3}$ In north American markets, transactions are either based on the LME price or on the daily marker price published in Metals Week, which tends to reflect north American market conditions more accurately than the London-based price. But in the absence of a liquid north American aluminium futures contract, the LME forms, either directly or indirectly, the effective price basis for the entire world,

\footnotetext{
${ }^{1}$ If prices are set by individual producers, they are forced to rely on their individual information sets. Instead, markets "aggregate" information. Bray (1981) showed that, under certain conditions, the forward price based on aggregated information is a sufficient statistic for the combined information possessed by individual traders. See also Kyle $(1984,1989)$, Stein (1985) and Leach and Madhavan (1992).

${ }^{2}$ Radetzki (1990, p.81) states that publication of this price was discontinued in 1991. In fact, publication continued but the term "certain other transactions" was dropped, reflecting more widespread use of non-producer metal.

${ }^{3}$ It is standard practice in non-ferrous metals to price against the LME (also Comex in the case of copper) cash (Settlement) price. This is facilitated on the LME by the day-of-delivery structure of LME futures contracts which results in a distinct contract maturing each trading day (ie each "prompt date"). In contrast to the situation in standard north American futures markets, there is therefore substantial liquidity in the LME cash contract.
} 
despite the fact that, as in all futures markets, deliveries to and from exchange warehouses form only a very small proportion of total trade in aluminium metal.

In what follows, we examine whether futures trading in aluminium resulted in increased or reduced variability of transactions prices. Metals producers and consumers are concerned with the prices at which they contract - transactions prices rather than the list prices advertised by producers or exchange prices per se. The fact that exchange prices are more variable than were list prices is not directly relevant to the question of the effects of exchange trading on the variability of transactions prices. In order to answer that question, and in the absence of any record of actual transactions prices, we need to show that both the LME cash price and the Metal Bulletin prices may be regarded as measures of underlying actual aluminium transactions prices. If this is indeed the case, we may then examine the effects of futures trading on price variability in aluminium by looking for changes in the variability of the Metal Bulletin price.

There has been a long debate as to whether futures trading stabilises cash prices. Futures trading allows non-commercial speculators to take positions in the commodity without their being obliged to hold the physical commodity. Friedman (1953 p.175) argued that speculation will tend to reduce price volatility because (a) speculation is stabilising only if it is profitable, and (b) a selection process will eliminate unprofitable speculators. The first element of this argument was attacked by Hart (1977) who showed that there is no general presumption that profitable speculation will be stabilising. The selection argument is not well supported by empirical evidence - see Stewart (1949), Houthaker (1957) and Edwards and Ma (1992).

Empirical studies of the effects of futures trading on cash prices include Gray (1963), Powers (1970), Peck (1976), Taylor and Leuthold (1974), Cox (1976), Tomek (1979-80), Weaver and Banerjee (1990) and Darrat and Rahman (1995). The consensus of these studies is that futures trading either reduces or does not increase cash price variability, although Tomek and Gray (1979-80) reach the reverse conclusion. $^{4}$

\footnotetext{
${ }^{4}$ A more recent literature looks at the volume-volatility link in futures trading but the issue here is of the effects on volatility of changes in trading volume in the context of an established futures market.
} 
The possibility of speculative bubbles and of non-fundamentals based speculation on exchange prices complicates the issue. ${ }^{5}$ Bubbles are probably less important in markets for industrial raw materials, where stock-consumption levels are typically sufficiently low to prevent substantial divergence of prices from use-values, than they are in forex or equity markets. However, non-fundamentals based speculation, such as momentum-based strategies, make it difficult for other agents to distinguish between price movements arising from genuine information and those which are not fundamentally-based (De Long et al, 1990a, 1990b; see also Shleifer, 2000). And although it is probably true that (as in Friedman) non-fundamental speculation will not make money in the long run, it is easy to bankrupt oneself by adopting a fundamental-based strategy in the face of a strong price trend in the opposite direction. Traders always advise "the trend is your friend".

In summary, the theoretical arguments are inconclusive, and this strongly suggests that we should look at empirical evidence. The most influential study on the effects of exchange-trading is Slade (1991). She analysed the variance of price returns for six non-ferrous metals and concluded that greater reliance on exchange quotations resulted in higher price variability through the nineteen eighties in comparison to the previous decade. We have argued elsewhere that there is no evidence for any long term increase in metals price volatility, and that Slade's conclusions are, in this respect, are dependent on the Hunt silver manipulation. However, Slade was correct in stating that producer list prices were less variable than exchange prices at the time both pricing bases were current - see Figuerola-Ferretti and Gilbert (2000). But this leaves open the issue of whether transactions prices were more or less variable than exchange prices at that time; or more or less variable than they have become subsequent to futures trading in aluminium.

One response is to suggest that the variability of prices is not per se important. Even if prices are more variable under the current exchange-pricing regime than they were under producer pricing, firms can now use liquid futures markets to offset this risk. In practice, however, hedging is costly, both because of commissions, roll costs, etc., but also because it requires management time, and, if not properly supervised,

\footnotetext{
${ }^{5}$ Manipulation is also a potential issue. However, there is little evidence of manipulation in the LME aluminium market - see Gilbert (1996).
} 
gives rise to new risks (Jorion, 1997, ch.2). If this is conceded, variability is indeed important.

The remainder of this paper falls into three sections. In Section 2 we discuss the data. In Section 3 we use simple econometric and statistical methods to describe the time series behaviour of aluminium prices. In Section 4 we adopt a moving window approach to analyse changes between exchange and reported transaction prices over time. Section 5 and 6 are concerned with price volatility. In Section 5, we ask whether the move to exchange trading of aluminium has increased the variability of aluminium transactions prices, and in Section 6, we perform an impulse response analysis on exchange and transactions volatilities. Section 7 contains conclusions.

\section{Price Data}

We have a complete daily series of LME cash settlement prices from July 1979 to June 2000. ${ }^{6}$ Aluminium was also traded in new York on Comex (now part of NYMEX) over the period 1982-1996, and a new contract has recently been introduced. This gives us a second series of daily quotations over a subset of our sample. ${ }^{7}$ Producer list prices are available on a monthly basis from 1970 to the end of 1985, when the practice of issuing list prices was abandoned. ${ }^{8}$ Finally, we have two sources of data for transaction prices, the first relating to the European and the second to the North American market.

For Europe, transactions prices are quoted, originally as relating to "certain other transactions", in the twice weekly trade journal Metal Bulletin. This has allowed us to construct a series of monthly averages covering the period 1970-99. ${ }^{9}$ The quotation basis is not entirely consistent over time, and there are some gaps, particularly in the nineteen seventies, during which the series was either not quoted or quotations were not revised. For North America, we have constructed a daily transaction price series over the period 1985 to 1997 from the trade journal Metals Week. This series has the advantage that it is available on a consistent daily basis,

\footnotetext{
${ }^{6}$ Sources: 1979-1988 - World Bureau of Metal Statistics, World Metals Statistics (various issues); 1989-2000 - http://www.lme.co.uk/HistData.htm .

${ }^{7}$ Source: Comex.

${ }^{8}$ Source: Non Ferrous Metals Data (various issues).

${ }^{9} \mathrm{We}$ gratefully acknowledge financial support for the data compilation from the Social Science Faculty Research Fund, Queen Mary and Westfield College, University of London.
} 
while the European series is intermittent and of variable consistency, but it was not quoted during the producer pricing period of the nineteen seventies and early eighties. The European series is therefore potentially the more informative in relation to the impact of exchange trading on the variability of aluminium prices. (Of course, the north American and European series relate to different geographical markets and cannot be taken as measuring precisely the same price).

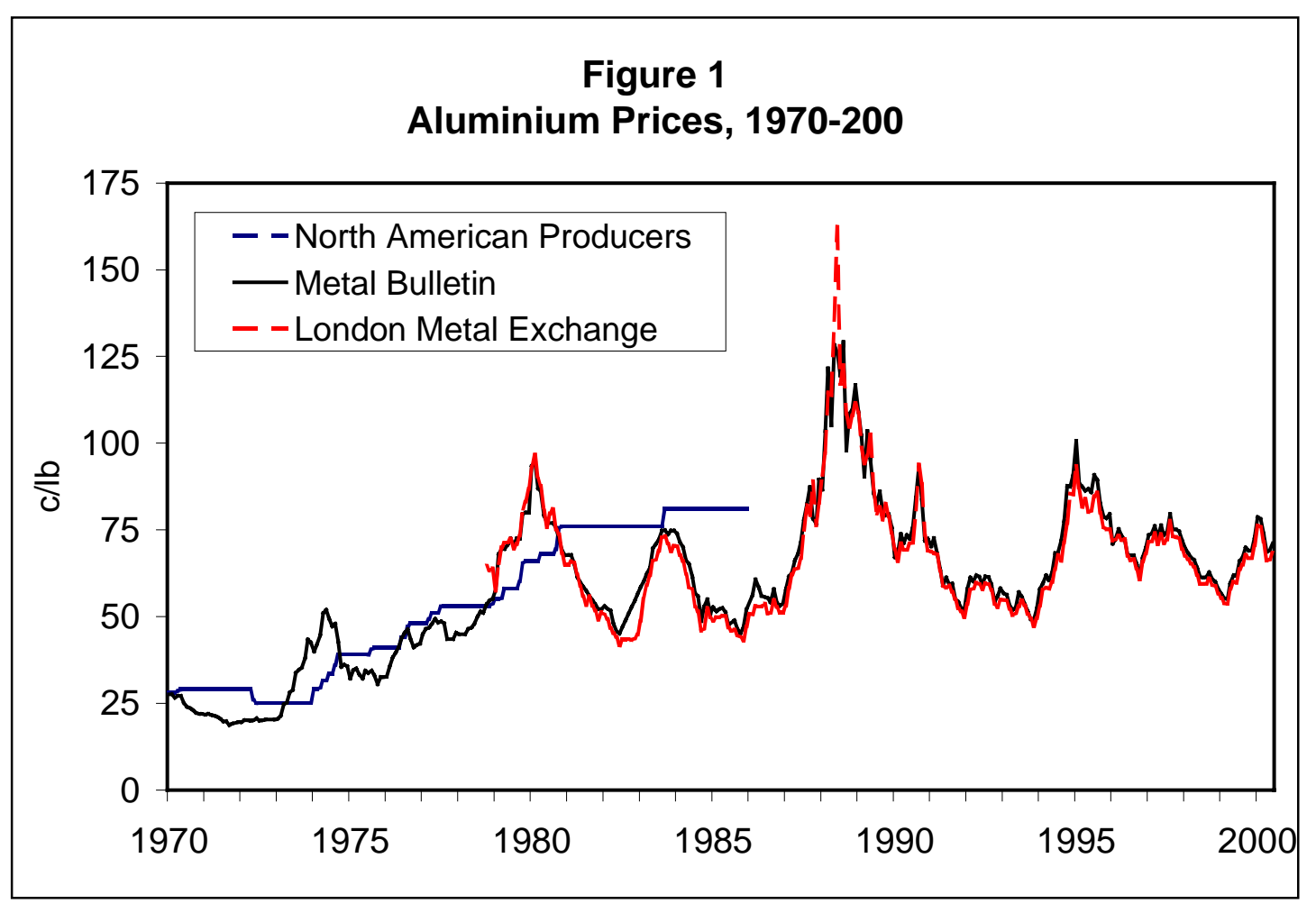

In Figure 1 we plot monthly averages of the North American producer list prices, the LME aluminium prices and the Metal Bulletin transactions prices over the full sample, January 1970 to June 2000. These graphs indicate the LME price is clearly more variable than the two producer prices. However, it is not immediately apparent whether the variability of the transactions price has or has not increased.

\section{Time Series Analysis}

Figure 1 suggested that the Metal Bulletin transaction price moves closely with the LME exchange price over the period in which both have been quoted. This is exactly what casual experience with the industry would suggest, but it is important to 
confirm this. If the two prices do indeed move closely together, they may both be taken as measuring the same thing - the price aluminium consumers pay for their metal. Both price series appear to have a common upward trend. This suggests it is reasonable to regard this common trend as a measure of the actual transactions price, with the two measured prices differing from this by trendless measurement errors.

We formalize this hypothesis in section 4 , while in this section we consider a simple statistical implication of the hypothesis. On this hypothesis, the difference between the two measured prices will be trendless - implying that the two measures are cointegrated. If this can be established, it is reasonable to take the Metal Bulletin price trend as measuring transactions prices also prior to the start of exchange trading. This will allow us to compare price variability before and after the start of exchange trading.

We first establish that both prices are non-stationary. Table 1 gives $\operatorname{ADF}(1)$ and $\mathrm{ADF}(3)$ statistics for the monthly averages of the logarithms of the LME and Metal Bulletin prices ( $\ln L M E$ and $\ln M B$ respectively) and their first differences over the sample of monthly data January 1979 - June 2000. (The ADF(3) statistics are included as a robustness check - there is no indication that anything more than a single lag is required to obtain serially independent errors). These tests establish that both prices are I(1) and therefore non-stationary.

\begin{tabular}{|l|r|r|r|r|r|}
\hline \multicolumn{7}{|c|}{ Table 1: Stationarity and Cointegration Tests } \\
\hline & $\ln L M E$ & $\Delta \ln L M E$ & $\ln M B$ & $\Delta \ln M B$ & $\ln ($ LME/MB $)$ \\
\hline $\mathbf{A D F}(1)$ & -2.39 & -10.10 & -1.78 & -12.19 & -8.05 \\
\hline $\mathbf{A D F}(3)$ & -2.70 & -7.79 & -2.10 & -7.92 & -6.34 \\
\hline
\end{tabular}

Table 1 also reports (column 5) the ADF test on the difference between the two prices, which is confirmed as being $\mathrm{I}(0)$. This implies that the two prices are indeed cointegrated and may therefore be seen as measuring the same latent transactions price 


\section{Moving Window Latent Variable Analysis}

In this section we attempt a formal analysis of the variability of the latent aluminium transactions price based on the recorded LME and Metal Bulletin prices. However, in practice, it is unrealistic to suppose that the relationship between the LME and Metal Bulletin prices has been constant over time - the reality is that the LME price has become increasingly important over time. This argues against consideration of a constant parametric formulation of the latent variable hypothesis. Instead, we adopt a moving window analysis.

On the latent variable hypothesis, both the exchange and the trade journal prices are regarded as measuring this latent price subject to a measurement error. The analogy is with Friedman's permanent income model of consumption expenditures (Friedman, 1957) in which measured income differs from permanent income by transitory income, which may be regarded as a measurement error - see also Griliches (1977) and Zellner (1977). An advantage of this approach is that it leaves open whether the exchange of the trade journal price is the more accurate measure of actual transactions prices, and, in our implementation, allows the relative importance of these two measures to evolve over time.

Write the unobserved latent price as $\mathrm{Z}_{\mathrm{t}}$. We model the changes in the two observed prices as third order autoregressions, augmented by error correction terms. ${ }^{10}$

$$
\begin{gathered}
\Delta \ln L M E_{t}=\alpha_{0}+\Delta Z_{t}+\sum_{j=1}^{3} \alpha_{1 j} \Delta \ln L M E_{t-j}+\alpha_{2} \ln \left(\frac{L M E}{M B}\right)_{t-1}+\varepsilon_{1 t} \\
\Delta \ln M B_{t}=\beta_{0}+\Delta Z_{t}+\sum_{j=1}^{3} \beta_{1 j} \Delta \ln M B_{t-j}+\beta_{2} \ln \left(\frac{L M E}{M B}\right)_{t-1}+\varepsilon_{2 t}
\end{gathered}
$$

We may write this system as

$$
\begin{aligned}
\Delta \ln L M E_{t} & =\alpha_{0}+\sum_{j=1}^{3} \alpha_{1 j} \Delta \ln L M E_{t-j}+\alpha_{2} \ln \left(\frac{L M E}{M B}\right)_{t-1}+e_{1 t} \\
\Delta \ln M B_{t} & =\beta_{0}+\sum_{j=1}^{3} \beta_{1 j} \Delta \ln M B_{t-j}+\beta_{2} \ln \left(\frac{L M E}{M B}\right)_{t-1}+e_{2 t}
\end{aligned}
$$

\footnotetext{
${ }^{10}$ By the Granger Representation Theorem (Granger, 1986; Engle and Granger, 1987), cointegration of $\ln L M E$ and $\ln M B$ implies that one or both of these equations must contain an error correction term.
} 
where $e_{\mathrm{jt}}=\Delta Z_{\mathrm{t}}+\varepsilon_{\mathrm{jt}}(j=1,2)$. Assuming the two measurement errors are uncorrelated, ie $E\left(\varepsilon_{t} \varepsilon_{t}{ }^{\prime}\right)=\left(\begin{array}{cc}\omega_{1}^{2} & 0 \\ 0 & \omega_{2}^{2}\end{array}\right)$, and $\mathrm{E}\left(Z_{\mathrm{t}}^{2}\right)=\zeta^{2}$ with $\mathrm{E}\left(Z_{\mathrm{s}} Z_{\mathrm{t}}\right)=0$ for $s \neq t$, it follows that $E\left(e_{t} e_{t}{ }^{\prime}\right)=\left(\begin{array}{cc}\sigma_{1}^{2} & \rho \sigma_{1} \sigma_{2} \\ \rho \sigma_{1} \sigma_{2} & \sigma_{2}^{2}\end{array}\right)=\left(\begin{array}{cc}\omega_{1}^{2}+\zeta^{2} & \zeta^{2} \\ \zeta^{2} & \omega_{2}^{2}+\zeta^{2}\end{array}\right)$.

Define the noise-to-signal ratios $\lambda_{j}=\frac{\omega_{j}^{2}}{\zeta_{j}^{2}}=\frac{\sigma_{j}^{2}-\rho \sigma_{1} \sigma_{2}}{\rho \sigma_{1} \sigma_{2}}(j=1,2)$. Using the entire sample April 1979 to June 2000 we estimate $\lambda_{1}=0.481$ and $\lambda_{2}=0.485$, so the two prices appear to be equally affected by measurement error. ${ }^{11}$

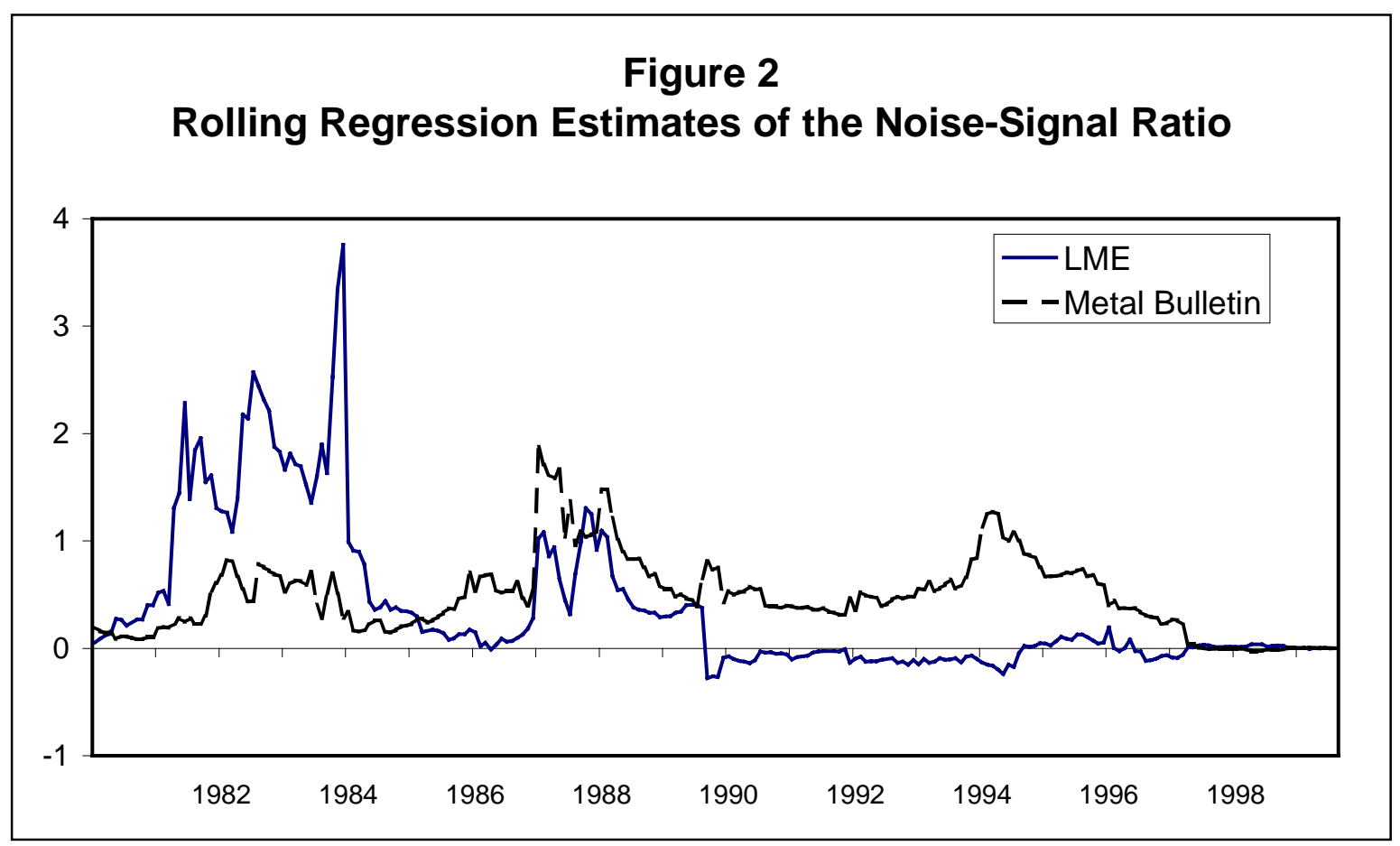

This model is exactly identified - there is the same number of parameters in the model as moments defined by the data implying that there are no testable overidentifying restrictions. We estimate the system using a rolling twenty-four month window. The estimated values of $\lambda_{1}$ and $\lambda_{2}$ are plotted in Figure 2. The plot shows that, if we accept this model as a valid representation of the relationship between the two prices,

\footnotetext{
${ }^{11}$ Observations for January - March 1979 are lost through lag creation. Full estimates are available from the first author on request.
} 
- The LME price was very noisy over the period 1980-84 while producers continued to set list prices.

- In the period 1985-90, the LME price became less noisy, but both this and the Metal Bulletin price continued to exhibit high noise-to-signal ratios. This was a period in which the prices of all non-ferrous metals were very volatile.

- During the period 1990-97, both price series appear to have become more accurate, with the LME price series, in particular, showing little evidence of measurement error.

- Finally, in the most recent period (1997-2000), the Metal Bulletin price series also shows little evidence of measurement error, consistent with the general move to pricing metals deliveries against the LME price.

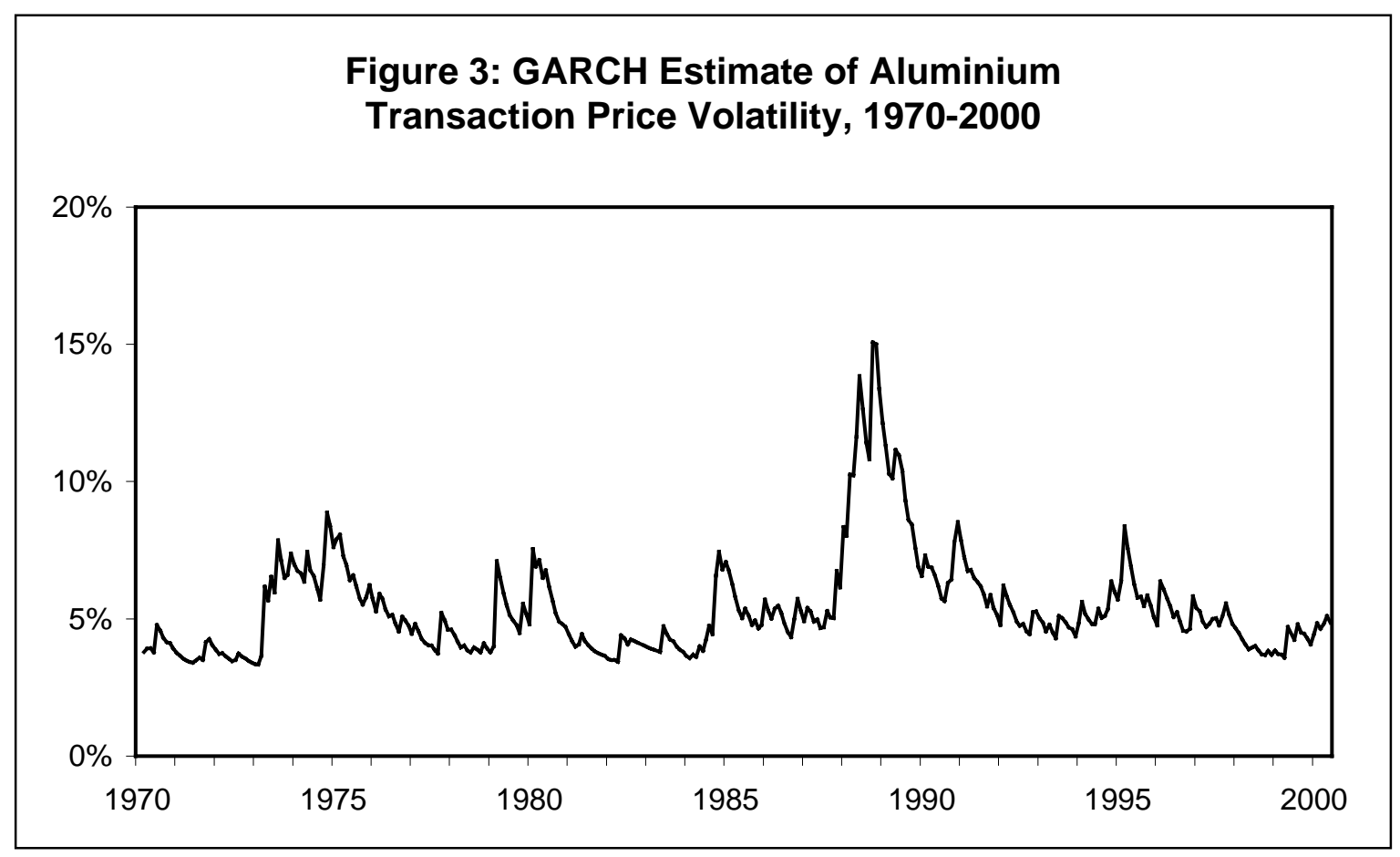

Although this falls short of a formal test, it does indicate that, if we do interpret both price variables as measuring underlying transactions prices with error, the resulting measurement errors have declined over time, most dramatically those associated with the LME price. This result, taken in conjunction with the earlier cointegration result, 
indicate that the measurement error interpretation of the LME and MB prices is acceptable. $^{12}$

\section{Price Volatility}

We measure price volatility as the standard deviation of price returns over each month for which we have data. Since Metal Bulletin prices are not available on a daily basis, we used their estimated conditional variance from a $\operatorname{GARCH}(1,1)$ regression model. ${ }^{13}$ The resulting annualized volatilities are graphed in Figure 3. There is no discernible trend, but periods of high volatility are evident in the mid nineteen seventies, the early eighties, and (particularly) the late eighties.

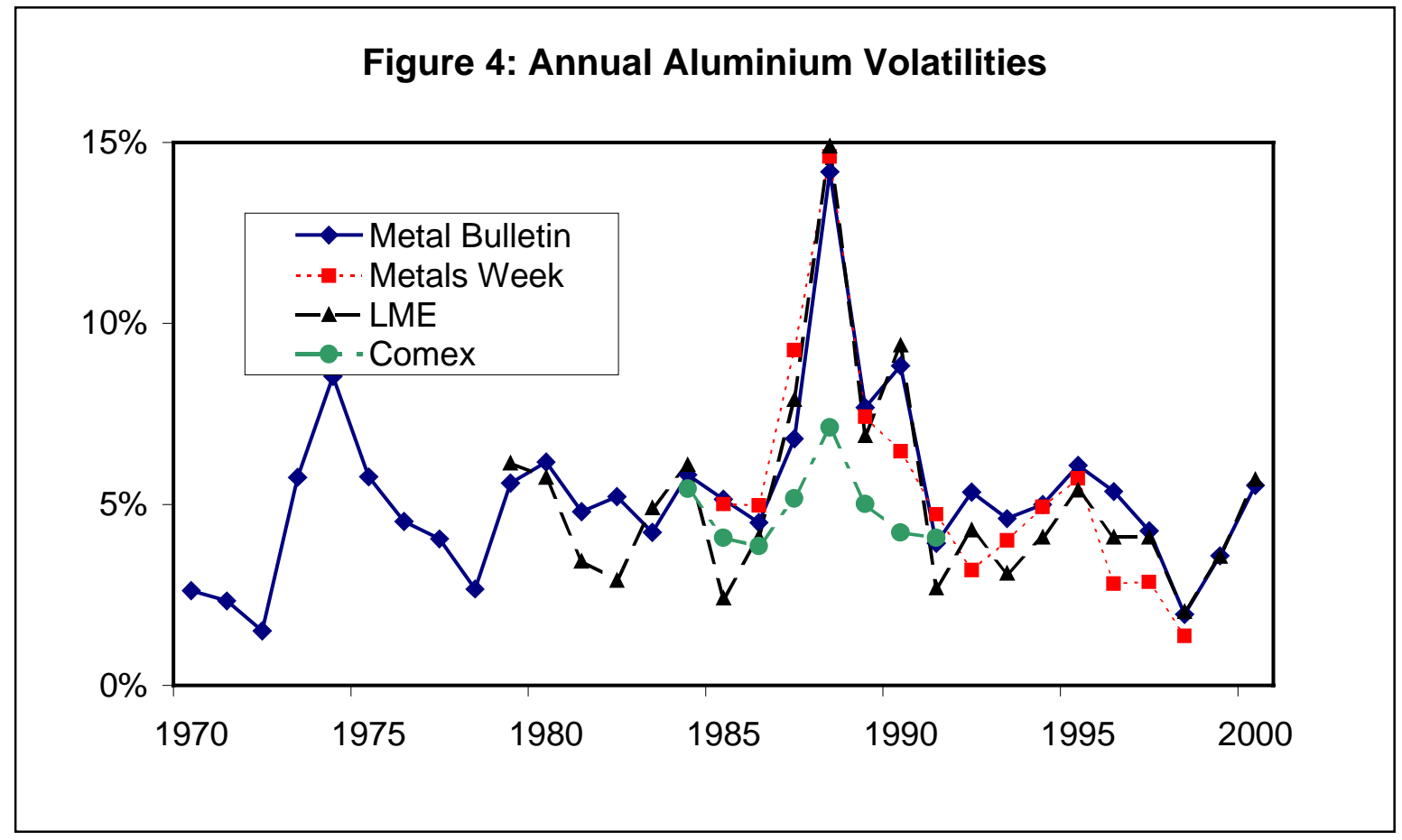

In Figure 4 we plot the intrayear standard deviations for the each of the Comex, LME and Metals Week price series together the annual average of the GARCH estimate of the Metal Bulletin price volatility. ${ }^{14}$ The four volatility estimates tell broadly the same story over the periods in which are they jointly available. The LME and Metal Bulletin volatilities appear to converge over the most recent years, while

\footnotetext{
${ }^{12}$ The estimated negative values for $\lambda_{1}$ in Figure 2 are inconsistent with this view. This may result from some smoothing of the Metal Bulletin price variance as a consequence of the reporting procedure.

${ }^{13}$ Engle (1982). See Bollerslev, Engle and Nelson (1994) for a summary. Estimation results available on request.
} 
the Metals Week volatility diverges more. This may reflect the European focus of the former pair of prices relative to the US focus of the latter. The Comex volatility is the most divergent, probably as the consequence of the low liquidity achieved by this contract.

Although the volatilities of the four price series broadly move together, the correlations are only modest. These are given in Table 2 for the sample of monthly data,1985-1990, for which we have all four quotations. ${ }^{15}$ Inspection of the time plots shows the LME and Metals Week prices as exhibiting very high volatility over 198788, while Comex and Metal Bulletin volatility rises less markedly.

\begin{tabular}{|c|c|c|c|c|}
\hline \multicolumn{5}{|c|}{ Table 2: Volatility Correlations, 1985-90 } \\
\hline & LME & Comex & $M B$ & $M W$ \\
\hline LME & 1.0000 & & & \\
\hline Comex & 0.7629 & 1.0000 & & \\
\hline$M B$ & 0.4756 & 0.4058 & 1.0000 & \\
\hline$M W$ & 0.9519 & 0.7445 & 0.4842 & 1.0000 \\
\hline
\end{tabular}

In Section 2 we showed that the Metal Bulletin transactions price moves closely with the LME price over the period in which they were both quoted and suggested that this allows us to take the Metal Bulletin price as a reasonable measure of the cost of aluminium in Europe both prior and subsequent to the introduction of the exchange trading of aluminium. We can test whether exchange trading increased the variability of the MB aluminium prices by performing an $F$ test on the variances before and after the start of exchange trading. We do his first using annual standard deviations calculated from monthly returns and then we repeat the procedure using the monthly $\operatorname{GARCH}(1,1)$ volatility estimates. ${ }^{16}$

\footnotetext{
${ }^{14}$ The 2000 volatilities are based on six months data.

${ }^{15}$ Although Comex traded through 1991, this was only expiring contracts, and the market was very thin.

${ }^{16}$ We convert returns calculated from monthly averages to annual returns using a conversion factor of 3. This is based on the volatility of monthly average returns which, on the assumption of temporal independence, is related to the volatility of daily returns by the proportionality factor $(4 n / 3)^{1 / 2}$, where $n$ is the number of trading days in the month. On the same assumption, the volatility of annual returns is related to the volatility of daily returns by the proportionality factor $m^{1 / 2}$, where $m$ is the number of trading days in the year.
} 


\begin{tabular}{|l|r|r|r|r|r|}
\hline \multicolumn{7}{|c|}{ Table 3: Metal Bulletin Price Volatilities } \\
\hline & Sample 1 & Sample 2 & Sample 3 & Sample 3a & Sample 3b \\
\hline Intrayear & $17.69 \%$ & $16.81 \%$ & $22.33 \%$ & $30.56 \%$ & $16.57 \%$ \\
\hline GARCH & $17.86 \%$ & $16.93 \%$ & $22.21 \%$ & $28.59 \%$ & $17.96 \%$ \\
\hline
\end{tabular}

In order to do this, we split the entire sample into three periods:

Sample 1: January 1970 - December 1978, prior to the start of exchange trading Sample 2: January 1979 - December 1985, the intermediate period in which the producer price functioned along side the exchange price.

Sample 3: January 1986 - June 2000 the post-producer pricing period.

Table 3 gives the estimated price volatilities of the Metal Bulletin price in these three sub-periods. Using both our measures, volatility is higher in Sample 3 than Sample 1. This appears to confirm that aluminium price volatility did indeed increase after the introduction of exchange trading. However, inspection of Figure 1 suggests that the high volatilities in the post-exchange trading period, Sample 3, may be entirely due to the high price volatility experienced in the late nineteen eighties. To investigate this, we divide sample 3 into

Sample 3a: January 1986-December 1990, and

Sample 3b: January 1991- June 2000.

On this basis, the increased volatility evident in Sample 3 appears to be entirely due to the very high volatility experienced in the late nineteen eighties (Sample 3a).

Volatility in he nineteen nineties (Sample 3b) is only slightly greater than that in the nineteen seventies (Sample 1).

We may formally test these impressions using the standard Fisher variance equality test - see Table 4. The first column tests equality of the volatilities in Sample 1 with those in Sample 3, while the second column performs the same test for Sample 1 against Sample 3b. In both cases the results are clear cut, confirming the impression deriving from the number in Table 3. The hypothesis of equal variances in Samples 1 and 3 is decisively rejected against the alternative of a higher variance in sample 3 , but the hypothesis that the variances were equal in Samples 1 and $3 \mathrm{~b}$ is not rejected. The late nineteen eighties (Sample 3a) appears to be an anomalous high volatility period. if we are prepared to ignore this period, aluminium price volatility appears neither higher nor lower than prior to the introduction of futures trading. 


\begin{tabular}{|l|l|l|}
\hline \multicolumn{3}{|c|}{ Table 4: Variance Equality Tests } \\
\hline & Sample 3 versus Sample 1 & Sample 3b versus Sample 1 \\
\hline Intrayear & $\mathrm{F}_{173,105}=1.59$ [tail 0.49\%] & $\mathrm{F}_{113,105}=0.88$ [tail 75.30\%] \\
\hline GARCH & $\mathrm{F}_{174,106}=1.55$ [tail 0.75\%] & $\mathrm{F}_{114,106}=1.01$ [tail $47.66 \%$ ] \\
\hline
\end{tabular}

Application of the Fisher F test to the estimated GARCH variances is not strictly valid since these will not in general be independent. However, an alternative GARCH-X procedure gives the same result. We extend the $\operatorname{GARCH}(1,1)$ model by including three intercept dummies relating to samples 2, 3a and $3 \mathrm{~b}$ :

$$
\sigma_{t}^{2}=h\left(1+\phi_{2} D_{2}+\phi_{3 a} D_{3 a}+\phi_{3 b} D_{3 b}\right)+\alpha \varepsilon_{t-1}^{2}+\beta \sigma_{t-1}^{2}
$$

The three dummies allow the mean of the GARCH process to vary across the four samples. Estimation results are given in Table 5

\begin{tabular}{|l|r|r|r|r|r|r|}
\hline \multicolumn{7}{|c|}{ Table5: GARCH-X estimates } \\
\hline & \multicolumn{1}{|c|}{$h$} & $\alpha$ & $\beta$ & \multicolumn{1}{c|}{$\phi_{2}$} & \multicolumn{1}{c|}{$\phi_{3 \mathrm{a}}$} & \multicolumn{1}{c|}{$\phi_{3 \mathrm{~b}}$} \\
\hline Coefficient & 0.000228 & 0.1209 & 0.7864 & -0.01500 & 1.75439 & 0.00583 \\
\hline$t$ ratio & 2.5162 & 2.8243 & 10.8522 & -0.0509 & 1.2068 & 0.0155 \\
\hline
\end{tabular}

The results show that none of the dummies are individually significant in explaining the conditional variance of Metal Bulletin prices. A likelihood ratio test (distributed as $\chi_{3}^{2}$ ) on their joint significance gave a value of 3.94 (tail probability 26.8\%), implying failure to reject the null hypotheses of $\phi_{2}=\phi_{3 \mathrm{a}}=\phi_{3 \mathrm{~b}}=0$. This test outcome is therefore consistent with a constant volatility process throughout the entire sample. However, the power of any test on GARCH estimates based on a relatively small number of observations may be low, and for this reason we prefer to rely on the traditional Fisher test.

\section{VAR Impulse Response Analysis}

Do volatility shocks in the aluminium market primarily arise in the futures exchange or during actual transactions? In this section we report the results of a VAR (Vector AutoRegression) analysis of aluminium volatilities which allows us to answer this question. By estimating a VAR on the monthly LME Metal Bulletin and Metals 
Week volatilities (VLME VMB VMW respectively), we can trace out the impact of shocks to the exchange and transactions volatilities. ${ }^{17}$ We started by estimating a VAR(2) over the sample January 1982 - June 2000. This allowed us to test the hypothesis that the three second lag coefficients are all zero $\left(\chi^{2}(9)=12.30\right)^{18}$ which permitted us to simplify to a VAR(1). Table 5 reports the resulting estimates.

The Metals Week price is seen as responding proportionately and very rapidly to the LME price while the Metal Bulletin price demonstrates a smoother reaction. There is clear evidence of a link from the LME and MW volatility series to the Metal Bulletin series and weak evidence of the reverse link. ${ }^{19}$ It is notable that the standard errors of the LME and Metals Week volatility series are around five times higher than that of the Metal Bulletin series.

\begin{tabular}{|l|c|c|c|}
\hline \multicolumn{4}{|c|}{$\begin{array}{c}\text { Table 6: VAR Estimates } \\
\text { (standard errors in parentheses) }\end{array}$} \\
\hline & $V L M E_{\mathrm{t}}$ & $V M B_{\mathrm{t}}$ & $V M W_{t}$ \\
\hline Intercept & 0.0075 & 0.0023 & -0.0020 \\
& $(0.0063)$ & $(0.0013)$ & $(0.0083)$ \\
\hline$V L M E_{\mathrm{t}-1}$ & 0.8473 & 0.1620 & 1.0627 \\
& $(0.1394)$ & $(0.0296)$ & $(0.1841)$ \\
\hline$V M B_{\mathrm{t}-1}$ & 0.2558 & 0.8609 & 0.3340 \\
& $(0.1214)$ & $(0.0257)$ & $(0.1602)$ \\
\hline$V M W_{\mathrm{t}-1}$ & -0.1941 & -0.0691 & -0.3020 \\
& $(0.1090)$ & $(0.0231)$ & $(0.1438)$ \\
\hline standard error. & 0.0286 & 0.0061 & 0.0378 \\
\hline residual correlations & 1.0000 & 0.2744 & 0.8570 \\
& & 1.0000 & 0.2662 \\
& & & 1.0000 \\
\hline
\end{tabular}

\footnotetext{
${ }^{17}$ Lütkepohl (1991), Favero (2000). See Charemza and Deadman (1987) for an introductory account. The VAR methodology is not strictly valid here since the Metal Bulletin volatility is obtained from a preliminary $\operatorname{GARCH}(1,1)$ while the VAR methodology treats these estimates as data. Caution should be exercised with regard to the quoted coefficient standard errors. ${ }^{18}$ Since $12.30<\chi^{2}(0.05,9)=16.92$ we fail to reject the null hypotheses of joint zero slopes for second lag variables.

${ }^{19}$ These conclusions are confirmed by Granger non-causality tests which reject the hypothesis that the LME volatility Granger non-causes the Metal Bulletin volatility $\left(\mathrm{F}_{2,196}=21.08\right)$ but fail to reject the hypothesis that the Metal Bulletin volatility Granger non-causes the LME volatility $\left(\mathrm{F}_{2,196}=2.85\right)$ at the $5 \%$ level. (The hypothesis is rejected at the $10 \%$ level). Our test results also reject the hypotheses that Metals Week volatility Granger non-causes the Metal Bulletin volatility $\mathrm{F}_{2,157}=6.171$ but fail to reject that the Metal Bulletin volatility Granger non-causes the Metals Week volatility $\mathrm{F}_{2,157}=1.95$. The hypothesis that LME volatility Granger non-causes Metals Week volatility is rejected at the $1 \%$ significance level whereas $\left(\mathrm{F}_{2,157}=16.35\right)$ the hypothesis that Metals Week volatility Granger non-causes LME volatility is only rejected at the $10 \%$ significance level $\left(\mathrm{F}_{2,157}=2.74\right)$.
} 
By using impulse response analysis, we are able to track the effects of a shock to each of the volatilities. We use one standard deviation shocks, with the implication that the quantitative effects are larger from the shock to the LME volatility. Because the VAR residuals are significantly correlated, the system does not possess a unique variance decomposition. We triangularize the residual variance matrix by imposing the ordering LME: Metals Week: Metal Bulletin.

The impulse response functions are graphed as Figures 5, 6 and 7, drawn on a common scale. They show the LME and Metals Week volatilities moving very closely together, with the Metal Bulletin volatility responding in a much more sluggish manner. It is clear that the Metal Bulletin price contributes very little to volatility movements. $^{20}$

Aluminium was not actively traded on any American futures exchange over most of the period we have examined. In this circumstance, the Metals Week price has assumed the role of a marker price for north American transactions. By contrast, the Metal Bulletin price measures actual transactions prices, which are often either based on an average of daily exchange prices or allow firms to choose on which days they price deliveries. These backpricing procedures generate the smoother volatility response patters exhibited in Figure 6. The estimates indicates that while most of the shocks to volatility arise from shocks to the volatility of the two marker prices, these decay rapidly and have only a modest impact on the transactions price volatility. Much of the exchange price variability may therefore be seen as "froth" with little relevance to actual pricing.

This may also explain the apparent greater variability of Metal Bulletin transactions prices in the post-producer pricing period. As transactions prices track the LME price increasingly closely, the extent to which they reflect the froth in the exchange prices has tended to increase. But because this froth rapidly evaporates, the

\footnotetext{
${ }^{20}$ This result is independent of the triangularization adopted. However, the relative ranking of the LME and Metals Week contribution is sensitive to which of these variables is regarded as independent.
} 
intrayear volatilities, based on the standard deviation of monthly prices, are little changed from historical levels. 
Figure 5

Impulse Response Function to a Unit S.D LME Volatility Shock

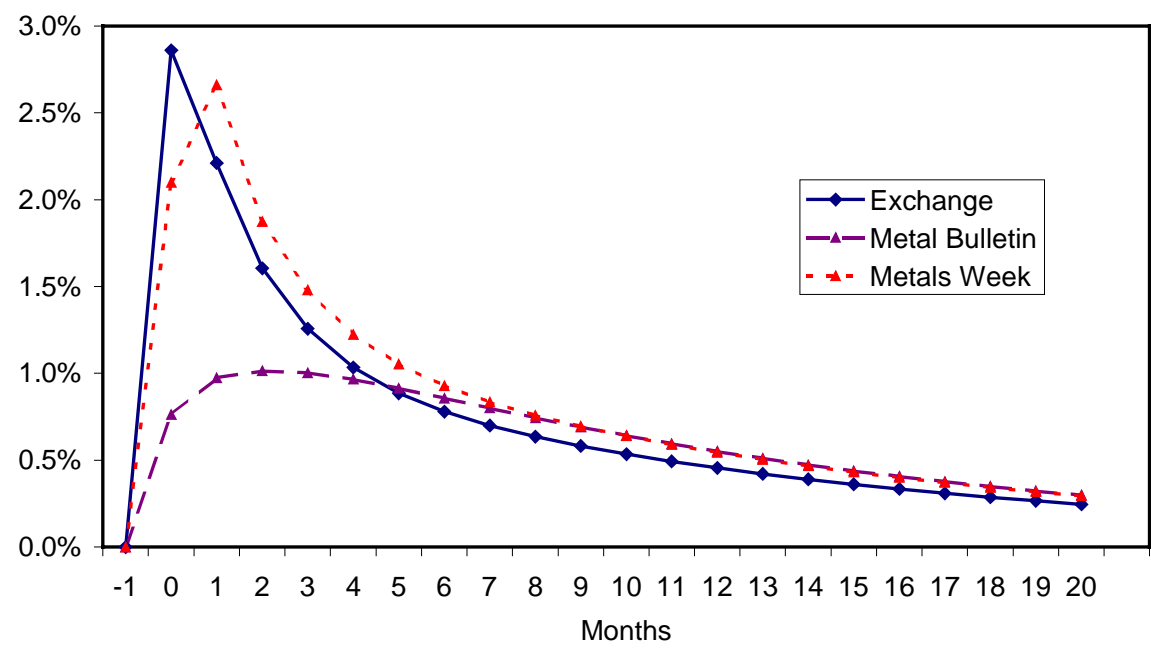

Figure 6: Impulse Response Function to a Unit S.D Metal Bulletin Volatility Shock

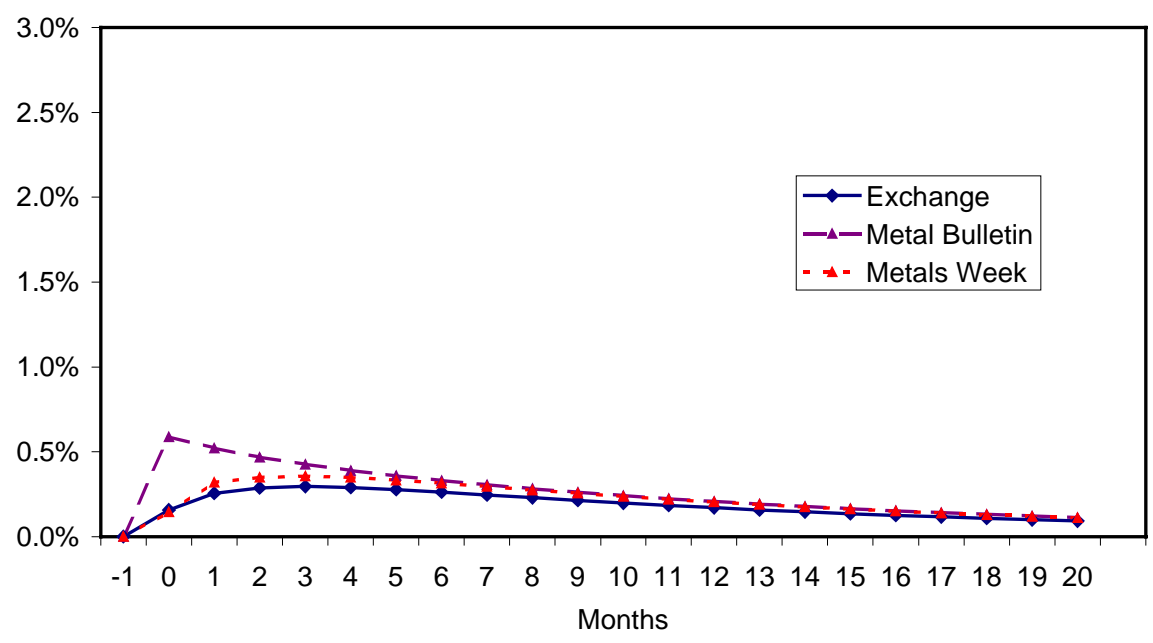

Figure 7: Impulse Response Function to a Unit S.D. Metals Week Volatility Shock

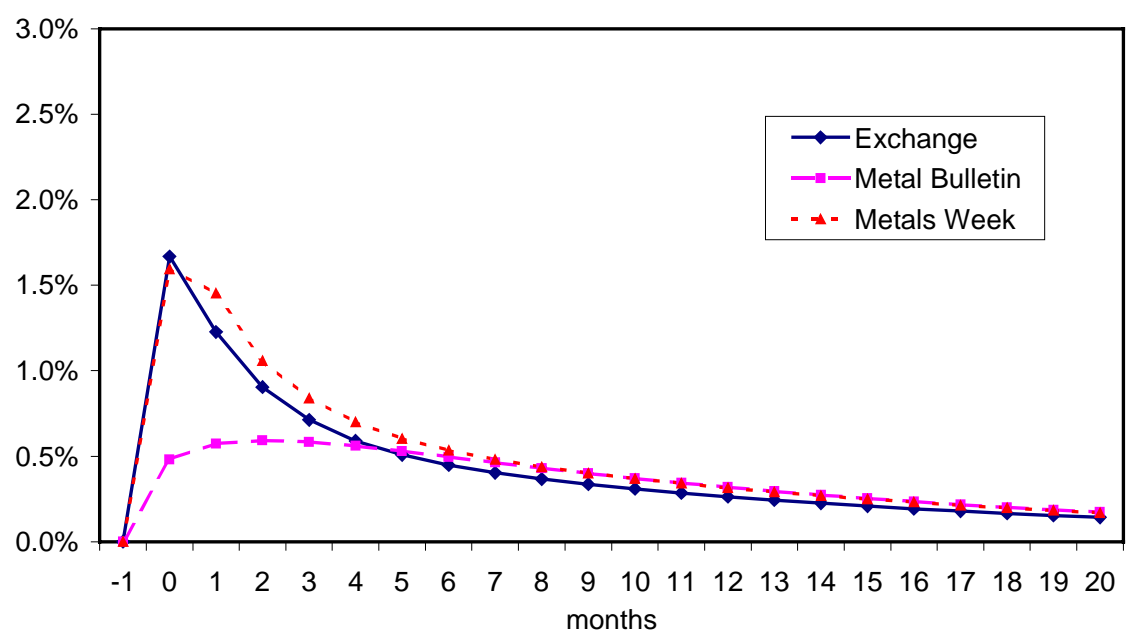




\section{Conclusions}

In this paper, we have used transactions prices for aluminium metal to examine whether the move from producer list pricing to exchange pricing has been associated with an increase in price variability (volatility). This involved our establishing that the transactions price and the exchange price are measures of the same underlying value. We justified this claim by showing

a) that the two prices are cointegrated, with the implication that any divergences between the two disappear over time, and

b) in a framework in which both prices may be regarded as measuring an unobserved latent value with error, the exchange price has become an increasingly accurate measure of that value.

Price volatility in the aluminium market showed an upward trend over the period in which exchange trading started and the exchange price became the established pricing basis. Volatility was particularly high in the final years of the nineteen eighties, but this was true also in other non-ferrous metals, notably copper. Volatility was much lower in the nineteen nineties, although slightly higher than the levels that prevailed prior to the introduction of exchange trading in the nineteen seventies. A formal statistical test failed to reject the hypothesis that the volatility of aluminium transactions prices differed in the nineteen nineties from its level prior to the introduction of futures trading in the nineteen seventies.

Attention tends to focus on the variability of exchange prices. Transactions prices are somewhat less variable than exchange prices, but, importantly, are less prone to sharp jumps. This "frothiness" of exchange prices attracts significant attention, but is probably of little relevance in the aluminium industry. The best judgement is therefore that there is weak evidence of a very modest increase in transactions price volatility over the period in which the industry has moved to an exchange pricing basis, but that this increased variability arises because transactions prices now reflect the rapidly decaying froth in exchange prices. 


\section{References}

Bollerslev, T., Engle, R.F., and D.B., Nelson (1994), “ARCH Models”, in Engle, R. F., and D. L. McFadden, eds. Handbook of Econometrics, Vol. IV, Ch. 49, Amsterdam, North-Holland.

Bray, M (1981), "Futures trading, rational expectations and the Efficient Markets Hypotheses", Econometrica, 49,575-96

Brunetti, C., and C.L. Gilbert (1995), "Metals price volatility, 1972-95”, Resources Policy, 21 (1995), 237-254.

Charemza, W., and Deadman, D. (1987), New Directions in Econometric Practice, Cheltenham, Edward Elgar.

Darrat, A.F., and S. Rahman (1995), "Has futures trading activity caused stock price volatility?", Journal of Futures Markets, 15, 537-57.

De Long, J.B., A. Shleifer, L. Summers, and R. Waldmann (1990a), "Noise trader risk in financial markets", Journal of Political Economy, 98, 703-38.

De Long, J.B., A. Shleifer, L. Summers, and R. Waldmann (1990b), "Positive feedback investment strategies and destabilizing rational speculation", Journal of Finance, 45, 375-95.

Edwards, F.R. and C. Ma (1982), Futures and Options, New York, McGraw-Hill.

Engle, R.F. (1982), “Autoregressive conditional heteroskedasticity with estimates of the variance of United Kingdom inflation", Econometrica, 50, 987-1007.

Engle, R.F., and C.W.J. Granger (1987), "Cointegration and error correction: Representation, estimation and testing", Econometrica, 55, 251-76.

Favero, C.A. (2000), Applied Macroeconometrics, Oxford, Oxford University Press.

Figuerola-Ferretti, I., and C.L. Gilbert (2000), "Price variability and marketing method in the non-ferrous metals industry", Vrije Univesiteit, Amsterdam, processed; available at http://www.econ.vu.nl/medewerkers/cgilbert/metals.htm

Friedman M.(1953), Essays in Positive Economics, Chicago: Chicago University Press.

Friedman, M. (1957), A Theory of the Consumption Function, New York, NBER.

Ghosh, S., C.L.Gilbert and A.J. Hughes Hallett (1987), Stabilizing Speculative Commodity Markets, Oxford, Oxford University Press.

Gilbert, C.L. (1996), "Manipulation of metals futures: lessons from Sumitomo”, CEPR Discussion paper. 
Granger, C.W.J. (1986), "Developments in the study of cointegrated economic variables", Oxford Bulletin of Economics and Statistics, 48, 213-28.

Gray, R.W. (1963), "Onions revisited”, Journal of Farm Economics, 45, 273-76; ; reprinted in Peck, A. (ed.), Selected Writings on Futures Markets, II, 319-22, Chicago, Chicago Board of Trade.

Griliches, Z. (1977), "Errors in variables and other unobservables", in D.J. Aigner and A.S. Goldberger (1977), Latent Variables in Socio-economic Models, North Holland.

Hart, O D (1977), "On the profitability of speculation", Quarterly Journal of Economics, 91, 579-97.

Houthaker, H.S. (1957), “Can Speculators forecast prices?”, Review of Economics and Statistics, 39, 73-87.

Jorion, P. (1997), Value at Risk, New York, McGraw-Hill.

Kyle, A.S. (1984), "Market structure, information, futures markets and price formation in international agricultural trade", in G. Story, A. Schmitz and A. Sarris eds., Advanced Readings in Price Formation, Market Structure and Price Instability, Boulder, Westview Press.

Kyles, A.S. (1989), "Informed speculation with imperfect competition", Review of Economic Studies, 56, 317-55.

Leach, J.C., and A.N. Madhavan (1992), "Intertemporal price discovery by market makers", Journal of Financial Intermediation, 2, 207-35.

Lütkepohl, H. (1991), Introduction to Multiple Time Series Analysis, Berlin, Springer.

Peck, A. (1976), "Futures markets, supply response and price stability”, Quarterly Journal of Economics, 90, 407-423; reprinted in Malliaris, A.G. (ed.), Futures Markets, II, 3-19, Cheltenham, Edward Elgar.

Powers, M.J. (1970), "Does futures trading reduce price fluctuations in cash markets", American Economic Review, 60, 460-64; reprinted in Malliaris, A.G. (ed.), Futures Markets, I, 309-13, Cheltenham, Edward Elgar.

Radetzki, M. (1990), A Guide to Primary Commodities in the World Economy, Oxford, Blackwell.

Shleifer, A. (2000), Inefficient Markets: An Introduction to Behavioral Finance, Oxford, Oxford University Press.

Slade, M. E. (1991), "'Market structure, marketing method, and price instability",, Quarterly Journal of Economics, 106, 1309-39. 
Stein, J.L (1985), "Futures markets, speculation and welfare", Department of Economics, Brown University, Working Paper 85-12.

Stein, J.L. (1986), The Economics of Futures Markets, Oxford, Blackwell.

Stewart, B (1949), “An analysis of speculative trading in grain futures', US Department of Agriculture, Technical Bulletin, 1001.

Taylor, G.S., and R.M. Leuthold (1974), "The influence of futures trading on cash price variation", Food Research Institute Studies, 13, 29-35; reprinted in Peck, A.Ed. (ed.), Selected Writings on Futures Markets, II, 323-29, Chicago, Chicago Board of Trade.

Tomek, W.G. (1979-80), "Futures trading and market information: some new evidence", Food Research Institute Studies, 17, 351-59.

Weaver, R.D., and A. Banerjee (1990), "Does futures trading destabilize cash prices? Evidence for U.S. live beef cattle", Journal of Futures Markets, 10, 41-60.

Zellner, A. (1977), "Estimation of regression relationships containing unobservable independent variables, in D.J. Aigner and A.S. Goldberger (1977), Latent Variables in Socio-economic Models, North Holland. 


\section{Q Queen Mary \\ University of London}

This working paper has been produced by the Department of Economics at Queen Mary, University of London

Copyright @ 2001 Isabel Figuerola-Ferretti and Christopher L. Gilbert. All rights reserved.

Department of Economics

Queen Mary, University of London

Mile End Road

London E1 4NS

Tel: +44 (0)20 78825096 or Fax: +44 (0)20 89833580

Email: j.conner@qmw.ac.uk

Website: www.econ.qmw.ac.uk/papers/wp.htm 